\title{
Influence of Inclined Magnetic Field on Carreau Nanoliquid Thin Film Flow and Heat Transfer with Graphene Nanoparticles
}

\author{
Noor Saeed Khan ${ }^{1, * \mathbb{D}}$, Taza Gul ${ }^{2}$, Poom Kumam ${ }^{3,4,5, * \mathbb{C}}$, Zahir Shah ${ }^{1}{ }^{(\mathbb{D}}$, Saeed Islam ${ }^{1}{ }^{(}$, \\ Waris Khan ${ }^{6}$ D, Samina Zuhra ${ }^{1,7}$ and Arif Sohail ${ }^{8}$ \\ 1 Department of Mathematics, Abdul Wali Khan University, Mardan 23200, Khyber Pakhtunkhwa, Pakistan; \\ zahir1987@yahoo.com (Z.S.); saeedislam@awkum.edu.pk (S.I.); samina.zuhra@abasyn.edu.pk (S.Z.) \\ 2 Department of Mathematics, City University of Science \& Information Technology, Peshawar 25000, \\ Khyber Pakhtunkhwa, Pakistan; tazagulsafi@yahoo.com.pk \\ 3 KMUTTFixed Point Research Laboratory, Room SCL 802 Fixed Point Laboratory, \\ Science Laboratory Building, Department of Mathematics, Faculty of Science, \\ King Mongkut's University of Technology Thonburi (KMUTT), Bangkok 10140, Thailand \\ 4 KMUTT-Fixed Point Theory and Applications Research Group, Theoretical and Computational Science \\ Center (TaCS), Science Laboratory Building, Faculty of Science, King Mongkut's University of Technology \\ Thonburi (KMUTT), Bangkok 10140, Thailand \\ 5 Department of Medical Research, China Medical University, Taichung 40402, Taiwan \\ 6 Department of Mathematics, Kohat University of Science \& Technology, Kohat 26000, Khyber Pakhtunkhwa, \\ Pakistan; wariskhan758@yahoo.com \\ 7 Department of Mathematics, Abasyn University, Peshawar 25000, Khyber Pakhtunkhwa, Pakistan \\ 8 Department of Mathematics, Islamia College University, Peshawar 25000, Khyber Pakhtunkhwa, Pakistan; \\ arif.sohail.khattak@gmail.com \\ * Correspondence: noorsaeedkhankhattak@gmail.com (N.S.K.); poom.kum@kmutt.ac.th (P.K.)
}

Received: 28 January 2019; Accepted: 9 April 2019; Published: 17 April 2019

\begin{abstract}
The thermodynamics of a Carreau nanoliquid thin film embedded with graphene nanoparticles past a stretching sheet is studied in the presence of inclined magnetic field and non-uniform heat source/sink. Graphene is a new two-dimensional amphiphilic macromolecule which has great applications due to its electrical and mechanical properties. The basic constitutive equations of Carreau nanoliquid for velocity and temperature have been used. Similarity transformations are adopted to achieve the nonlinear coupled differential equations accompanying boundary conditions embedded with different parameters. HAM (Homotopy Analysis Method) is used to solve the transformed equations for expressions of velocity and temperature. Graphs are shown which illustrate the effects of various parameters of interest. There exists a nice agreement between the present and published results. The results are useful for the thermal conductivity and in the analysis and design of coating processes.
\end{abstract}

Keywords: graphene nanoparticles; nanoliquid thin film; Carreau fluid; heat transfer; stretching sheet; homotopy analysis method

\section{Introduction}

Heat transfer is a crucial part of some areas like chemical industry, oil and gas, nuclear energy, electrical energy, etc. In the previous decades water, ethylene glycol, and oil were employed for the thermal conductivities, but for the growth of energy environments, nourishment of energy transferring dispersion accompanying enhanced heating conduction is still weak. The term nanofluids refers to dispersions containing nanosized particles having high thermal conductivity. Nano-dispersions are 
utilized to improve the thermo-physical properties like electrical conductivity, thermal diffusivity, and viscosity. It is noticed that thermal conductivity and viscosity are the integral parts in the heat transfer properties of nanoliquids. Convective heat transfer coefficient and pumping power of liquids are reliant on the fluid velocity and Prandtl number, which are controlled by the liquid viscosity.

The thermal conductivity is an important notion of the heat transfer nanoliquids. To enhance the thermal conductivity, different nanoparticles bear the range $0.001-50 \mathrm{wt} \%$ of different nanomaterials like carbon black, oxides, carbon nanotubes (CNT), nitrides, single-walled carbon nanotubes (SWNTs), multi-walled carbon nanotubes (MWNTs), metals, diamond, carbon fiber, graphite, graphene oxide, graphite flakes, and mixing of various shapes (particle, disk, tube, sheet, fiber, etc.) are used. This is required to obtain a reasonable stability of nanofluids. It is most important and necessary for the huge applications of nanofluids that the dispersion should be good and of high stability.

Graphene is used as nanoparticle due to its various preferred and superior qualities like low cost and better thermal conductivity. Graphene consists of a single-entity-thick sheet having the shape of a hexagon lying in $s p^{2}$ hybridization in carbon atoms, and has applications due to thermal, electrical, optical, mechanical, and other relevant characteristics. Graphene is a transparent conductor that can be used to replace the current bearing liquid crystal display materials. The elastic modulus of the theoretical calculations and experimental measurements are 1.05-1.24 TPa and $1 \mathrm{TPa}$, respectively. The thermal conductivity of graphene is up to $5300 \mathrm{Wm}^{-1} \mathrm{~K}^{-1}$. At normal heat transfer, the conduction capability of graphene is highly appreciated as having the value $15,000 \mathrm{Wm} \mathrm{cm}^{2} \mathrm{~V}^{-1} \mathrm{~s}^{-1}$ and its carrier mobility is not affected by temperatures in the range of 10-100 K, which proves that defect scattering is the main scattering mechanism of the electrons in graphene. Graphene's inimitable electronic properties make it a new infrared frequency domain plasmon waveguid and terahertz metamaterial. By excitation of photons or electrons, the collective oscillation of electrons on the surface of a conductor is the surface plasmon. When photons and graphene's surface are coupled, they form surface plasmon polaritons. The confocal micro-Raman spectroscopy is used to measure the heat transport of the suspended graphene nanoparticles. The thermal conductivity reaches $3500-5300 \mathrm{~W} / \mathrm{mK}$ and the average independent wavelength of the photons is $775 \mathrm{~nm}$ at normal heating. The type of general matter change directly modifies or improves few features of substances by combining various substances to make hetrostructure and doping. More vastly, due to the graphene atomic-level thin film feature, its geometry and edge confirmation due to irregular structure as well as armchair structure bear a high influence on capability. By the modification of graphene geometry, the modification in size structure geometry, the doping of other atoms, and the synthesis of a hetrostructure, the modification of charge bearing, heating, thermal and electrical features of graphene bring a vast usage in other relevant fields.

Considering theoretical study on graphene, Khan et al. [1] presented a novel study about the strong applied magnetic field on Eyring Powell graphene liquid film past an unsteady stretching sheet in which the velocity reduces with increasing concentration of graphene nanoparticles. Sandeep and Malvandi [2] reported the study on graphene nanofluids, simultaneously detecting the behaviors of three non-Newtonian nano-dispersions of Jeffery, Maxell, and Oldroyd-B in the presence of transverse magnetic field. They obtained the results that motion becomes fast with increasing graphene nanoparticles concentration. Zuhra et al. [3] also provided the solution of a problem of graphene nanoliquid films (Casson and Williamson) using homotopy analysis method where velocity is found to tend to decrement.

On the basis of extensive experimental graphene applications, Wu et al. [4] presented an effective preparation of nitrogen-doped graphene applying low heating. They used such a procedure which retains the processes of carbon allotrope oxygenation, exfoliation, and reduction through chemical process in combination with the application of hydrazine as a reducing agent, which shows reducing graphene oxidation and doping graphene accompanying atoms of nitrogen. Their work shows that nitrogen-doped graphene exhibits superior electrolytic activity towards $\mathrm{H}_{2} \mathrm{O}_{2}$ reduction. They also discussed the participation of doped nitrogen entities to the improved electrolytic work pertaining 
to density performance. Yue et al. [5] applied the concept of suppressing graphene aerogels' thermal conductivity by launching defects or doping entities in graphene. They prepared the nitrogen-doped (N-doped) graphene aerogels accompanying minimum heating conduction and by introducing doping entities and bridging factor by $\mathrm{CO}_{2}$ supercritical, the solid heating conduction was low. Sadeghinezhad et al. [6] performed experimental investigations to compute the energy transmission features and the pressure drop of a graphene nano-dispersion in underlying tube made of stainless steel that works under the uniform energy flow at its external side. They measured the heating conduction and viscous form of the graphene nanoplatelet nanofluid at specific saturations before an energy transmitting experiment. Guo et al. [7] synthesized nitrogen-doped graphene hydrogels (NGHs) by a single-pot hot rout accompanying graphene oxide as raw substance and urea used as reducing doping factor. Mehrali et al. [8] prepared nitrogen-doped graphene (NDG) nano-dispersion accompanying different concentration of ultra-fine particles applying the two-steps process in water dispersion as a base. In their work, the heating conduction of nano-dispersion was improved by particle saturation and heating, where the highest improvement was near $36.78 \%$ to a particle loading of $0.06 \mathrm{wt} \%$. In another study, Meharali et al. [9] employed organized procedures applied to make a good stable nitrogen-doped graphene (NDG) nano-dispersion. The impacts of various representatives like saturation, particle type, reaction duration heating conduction, and stability of nitrogen-doped graphene nano-suspension were explored practically. They showed that particle dispersion having $60 \mathrm{~min}$ probe and triton $X-100$ as a particle had high stability up to 6 months and the heating conduction of nitrogen-doped graphene particle dispersion was improved by nitrogen-doped graphene as nano-participant and suggesting formulations which focus on amount of ultra-fine particles in suspension, combining layer, and entity dimension. Also, their results obtained the best values very close to the practical values and provided improved signals about the heating conduction of nitrogen-doped graphene nano-dispersions compared to the recent formulations like Maxwell and Nan's model. Sheng [10] modulated the electrical and chemical features of graphene by combining other atoms and active moieties by supposing a facile, independent of catalysis heating painting process to a high rate preparation of nitrogen doped graphene applying minimum-price industrial substance melamine used as source of nitrogen. A clear X-ray curves due to photo electric effect contents of the achieved product detects that the participation of nitrogen atoms in doped graphene samples is $10.10 \%$. Reddy et al. [11] worked on a fixed development of nitrogen-doped graphene layers through dispersion precursor reliant to chemical vapor accumulation procedure. It was proved that nitrogen-doped graphene was developed quickly on copper-charged collectors and discussed for its Li-ion interaction features. More uses and studies of Newtonian, non-Newtonian, and nanofluids can be seen in the references [12-24].

Recently, the thermodynamics of suspension on surfaces (stretching/shrinking) is a topic of active research on behalf of its excessive usages in technological science, particularly in biomedical field as neurological treatment, food and polymer processing, in cancer treatment, blood flows, treatment of diagnosed diseases, etc. It is important to note that the shear rate and shear stress are as nonlinear variations to non-Newtonian fluids. Among non-Newtonian dispersions, Carreau dispersion is a well-known dispersion. At the excessive shear rate, the Carreau liquid behaves as power law dispersion, while at minimum shear rate it acts as a Newtonian fluid. In 1972, Carreau proposed a Carreau liquid formulation. Sulochana and Ashwinkumar [25] investigated the thermodynamics of magnetic thin liquid nanofluids film of $\mathrm{Fe}_{3} \mathrm{O}_{4}$-water and $\mathrm{CoFe}_{2} \mathrm{O}_{4}$-water Carreau model in which the power of applied magnetic field controls the thermal conductivity and causes aeolotropic. Raju et al. [26] presented the computational study of magnetic-Carreau fluid through dispersion retaining gyrotactic microorganisms on a slendering space considering variable thickness. They applied the combined effects of multiple slip and Soret with Dufour for the thermodynamics phenomena and solved the problem through Runge-Kutta-based Newton's method. Irfan et al. [27] applied convective boundary conditions to the significant contribution of Arrhenius activation energy with binary chemical reaction in unsteady Carreau nano-dispersion flow with magnetohydrodynamic effects using a numerical approach through the bvp4c scheme. Their outcomes show that velocities enhance with an increment 
in the power law index while temperature rises through the increment of thermal Biot number, radiation, and Brownian motion parameters. Waqas et al. [28] solved the problem of MHD Carreau nanofluid numerically using RK-45. They showed that the nanofluid velocity slows down for the local Weissenberg number in case of shear thinning and it speeds up for the shear thickening fluid. Mahmoud and Megahed [29] reported the slip effect on flow of time dependent Eyring Powell thin liquid film over a space accompanying heating conduction. They observed that as the slip velocity increases, the film thickness decreases.

The literature contains rich studies about the experimental work of graphene but there are very few theoretical studies investigating problems containing graphene nanoparticles. Similarly, there exists study [25] with different nanomaterials for Carreau thin film liquid but no studies on graphene nanoparticles taking into account the present theme exists. So the present problem considers an unsteady thermodynamics of Carreau thin nanoliquid with inclined magnetic field.

\section{Materials and Method}

\section{Problem Formulation}

An unsteady, two dimensional, electrically conducting liquid film with stretching velocity $U_{w}(x, t)=c x(1-\alpha t)^{-1}$ is studied. The situation that $c>0$, represents stretching and $\alpha t<1$. The $y$-axis exists perpendicular to the stretched space. By taking into account $T_{0}$ and $T_{r e f}$ as the slit and reference temperatures such that $T_{w}(x, t)=T_{0}+T_{r e f}\left(\frac{c x^{2}}{2 v_{f}}\right)(1-\alpha t)^{-\frac{1}{2}}$ is the fluid temperature at the wall. An external inclined magnetic field $B(t)=B_{0}(1-\alpha t)^{-\frac{1}{2}}$ implementation to the space at an angle $A$ is done which as viewed in Figure 1. The impact of induced magnetic field tends to vanish.

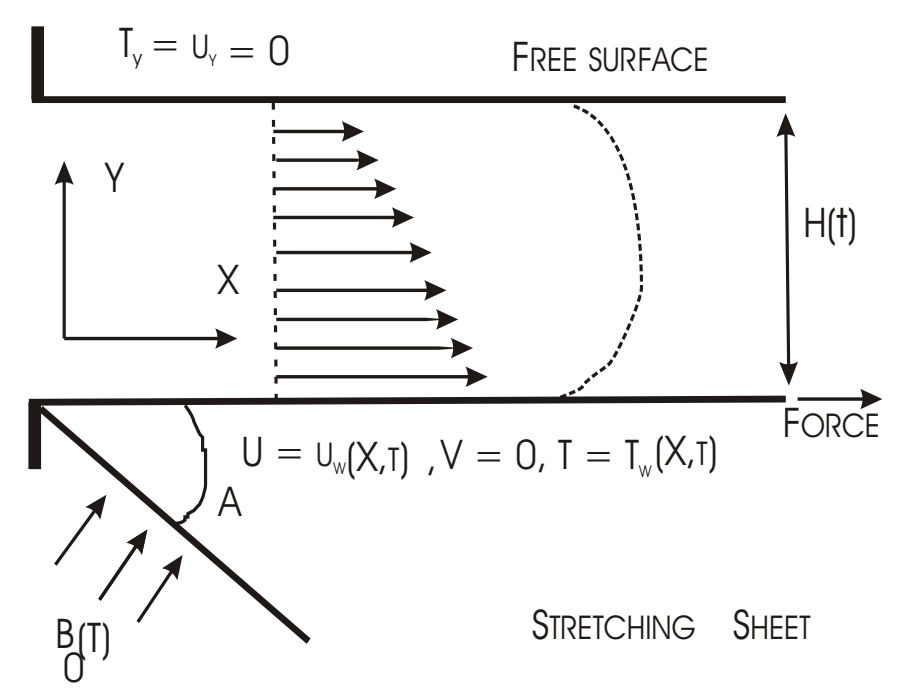

Figure 1. Geometry of the unsteady problem.

Formulation of a Carreau fluid is presented, as in [25], by

$$
\tau_{i j}=\mu_{0}\left[1+\frac{n-1}{2}\left(\Gamma \gamma_{i j}\right)\right] \gamma_{i j}
$$

$\gamma$ is defined as

$$
\gamma=\sqrt{\frac{1}{2} \sum_{i} \sum_{j} \gamma_{i j} \gamma_{j i}}=\sqrt{\frac{1}{2}} \prod
$$


Using the above assumptions, the problem formulation becomes

$$
\begin{gathered}
\frac{\partial u(x, t)}{\partial x}+\frac{\partial v(x, t)}{\partial y}=0, \\
\rho_{n f}\left[\frac{\partial u(x, t)}{\partial t}+u(x, t) \frac{\partial u(x, t)}{\partial x}+v(x, t) \frac{\partial u(x, t)}{\partial y}\right]=\mu_{n f} \frac{\partial^{2} u(x, t)}{\partial y^{2}}\left[1+\frac{3(n-1) \Gamma^{2}}{2}\left(\frac{\partial u(x, t)}{\partial y}\right)^{2}\right]- \\
\sigma_{n f} B^{2}(x, t) u(x, t) \cos ^{2} A, \\
\left(\rho c_{p}\right)_{n f}\left(\frac{\partial T(x, t)}{\partial t}+u(x, t) \frac{\partial T(x, t)}{\partial x}+v(x, t) \frac{\partial T(x, t)}{\partial y}\right)=k_{n f} \frac{\partial^{2} T(x, t)}{\partial y^{2}}-\frac{\partial q_{r}}{\partial y}+ \\
\frac{k_{f} u_{w}(x, t)}{x v_{f}}\left[A_{3}\left(T_{w}(x, t)-T_{0}(x, t)\right) f^{\prime}(\zeta)+A_{4}\left(T(x, t)-T_{0}(x, t)\right)\right],
\end{gathered}
$$

The assisting information is provided as

$$
\begin{gathered}
u=U_{w}(x, t), \quad v=V(x, t)=0, \quad T=T_{w}(x, t), \quad \text { at } \quad y=0, \\
\frac{\partial u(x, t)}{\partial y}=\frac{\partial T(x, t)}{\partial y}=0 \quad \text { at } \quad y=H, \quad v=\frac{d H}{d t} \quad \text { at } \quad y=H(t),
\end{gathered}
$$

By Rosseland approximation [25], the radiation flux is

$$
q_{r}=-\frac{4 \sigma_{1}}{3 k_{1}} \frac{\partial T^{4}}{\partial y}
$$

Applying Taylor's theorem

$$
T^{4}=4 T_{\infty}^{3} T-3 T_{\infty}^{4}
$$

using Equation (9), Equation (8) develops

$$
\frac{\partial q_{r}}{\partial y}=-\frac{16 T_{\infty}^{3} \sigma_{1}}{3 k_{1}} \frac{\partial^{2} T}{\partial y^{2}}
$$

For the graphene nanoparticles concentration the following relations are hold

$$
\begin{gathered}
\frac{\mu_{n f}}{\mu_{f}}=\frac{1}{(1-2.5 \phi)}, \quad \frac{\rho_{n f}}{\rho_{f}}=1-\phi+\phi r, \quad \frac{\left(\rho c_{p}\right)_{n f}}{\left(\rho c_{p}\right)_{f}}=1-\phi+\phi d, \\
\frac{k_{n f}}{k_{f}}=1+\frac{3(k-1) \phi}{k+2}, \quad \frac{\sigma_{n f}}{\sigma_{f}}=\frac{3(\sigma-1) \phi}{(\sigma+2)-(\sigma-1) \phi}+1 .
\end{gathered}
$$

Table 1 shows the different features of water and graphene nanoparticles.

Table 1. Different aspects of $\mathrm{H}_{2} \mathrm{O}$ and tiny particles.

\begin{tabular}{lll}
\hline Aspects & Pure Water & Graphene \\
\hline$\rho\left(\mathrm{kg} / \mathrm{m}^{3}\right)$ & 997 & 2250 \\
$\mathrm{c}_{p}(\mathrm{~J} / \mathrm{kg} \mathrm{K})$ & 4076 & 2100 \\
$k(\mathrm{~W} / \mathrm{m} \mathrm{K})$ & 0.605 & 2500 \\
$\sigma(\Omega \mathrm{m})^{-1}$ & 0.005 & $1 \times 10^{7}$ \\
\hline
\end{tabular}


Consider the following transformations

$$
\psi(x, y, t)=x\left(\frac{c v_{f}}{1-\alpha t}\right)^{\frac{1}{2}} f(\zeta), \quad T(x, y, t)=T_{w}-T_{r e f}\left[\frac{c x^{2}}{2 v_{f}}\right](1-\alpha t)^{-1.5} \theta(\zeta), \quad \zeta=\left[\frac{c}{v_{f}(1-\alpha t)}\right]^{\frac{1}{2}} y=\frac{\beta}{H(t)} y,
$$

where $u=\frac{\partial \psi}{\partial y}$ and $v=-\frac{\partial \psi}{\partial x}$.

Equation (13) easily justifies Equation (3). Using Equation (13) in Equations (4)-(7), four equations (14)-(17) are obtained

$$
\begin{gathered}
\phi_{1} f^{\prime \prime}\left[1+\frac{3(n-1)}{2} W e\left(f^{\prime \prime}\right)^{2}\right]+\phi_{2} \beta^{2}\left[f f^{\prime \prime}-\left(f^{\prime}\right)^{2}-S\left(f^{\prime}+\frac{\zeta}{2} f^{\prime \prime}\right)\right]-\phi_{3} M f^{\prime} \cos ^{2} A=0, \\
\left(\phi_{4}+N r\right) \theta^{\prime \prime}-\phi_{5} \operatorname{Pr} \beta^{2}\left[2 f^{\prime} \theta-f \theta^{\prime}+\frac{3}{2} S \theta+\frac{1}{2} S \zeta \theta^{\prime}\right]+A_{3} f^{\prime}+A_{4} \theta=0, \\
f=0, \quad \theta=1, \quad f^{\prime}=1 \quad \text { at } \quad \zeta=0, \\
f=\frac{\beta S}{2}, \quad \theta^{\prime}=f^{\prime \prime}=0 \quad \text { at } \zeta=\beta,
\end{gathered}
$$

The different parameters in Equations (14)-(17) are formulated as $\phi_{1}=\frac{\mu_{n f}}{\mu_{f}}, \phi_{2}=\frac{\rho_{n f}}{\rho_{f}}, \phi_{3}=\frac{\sigma_{n f}}{\sigma_{f}}$, $\phi_{4}=\frac{k_{n f}}{k_{f}}, \phi_{5}=\frac{\left(\rho c_{p}\right)_{n f}}{\left(\rho c_{p}\right)_{f}},(W e)^{2}=\frac{c^{3} x^{2} \Gamma^{2}}{v_{f}(1-\alpha t)^{3}}, S=\frac{\alpha}{c}, M=\frac{\sigma_{f} B_{0}^{2}}{c \rho_{f}}, N r=\frac{16\left(\sigma_{1}\right)_{f} T_{0}^{3}}{3 k_{1} k_{f}}$, and $\operatorname{Pr}=\frac{\left(\mu c_{p}\right)_{f}}{k_{f}}$. Note that in Equation (14) for $n=1$ or $W e=0$, the study converts to the hydrodynamic viscous fluid flow.

The local skin friction coefficient $C_{f_{x}}$ and the local Nusselt number $N u_{x}$ are formulated as

$$
C_{f}=\frac{\tau_{w}}{\rho_{f} U_{w}^{2}}, \quad N u=\frac{q_{w} x}{k_{f}\left(T_{w}-T_{0}\right)},
$$

where

$$
\tau_{w}=-\left[\mu_{n f} \frac{\partial u}{\partial y}\right]_{y=0}, \quad q_{w}=-k_{n f}\left[\frac{\partial T}{\partial y}\right]_{y=0}-\frac{4 \sigma_{1}}{3 k_{1}}\left[\frac{\partial T^{4}}{\partial y}\right]_{y=0} .
$$

Substituting Equation (19) in Equation (18) and applying Equation (13), the following equations are obtained

$$
C_{f_{x}}=-\left(R e_{x}\right)^{-\frac{1}{2}} \frac{1}{\beta} \frac{1}{(1-2.5 \phi)}\left[f^{\prime \prime}(0)\right], \quad N u_{x}=-\left(\operatorname{Re}_{x}\right)^{\frac{1}{2}} \frac{1}{\beta} \frac{k_{n f}}{k_{f}}(1+N r)\left[\theta^{\prime}(0)\right],
$$

where $\operatorname{Re}_{x}=\frac{U_{w} x}{v_{f}}$.

\section{Computation of the Transformed Equations Via HAM}

$$
\begin{array}{ll}
f_{0}(\zeta)=\zeta, & \theta_{0}(\zeta)=1, \\
\boldsymbol{L}_{f}=f^{\prime \prime \prime}, & \boldsymbol{L}_{\theta}=\theta^{\prime \prime}
\end{array}
$$

while

$$
\boldsymbol{L}_{f}\left[C_{1}+C_{2} \zeta+C_{3} \zeta^{2}\right]=0, \quad \boldsymbol{L}_{\theta}\left[C_{4}+C_{5} \zeta\right]=0,
$$

\subsection{Zeroth-Order Deformation Problems}

$\aleph_{f}$ and $\aleph_{\theta}$ are presented as

$$
\begin{aligned}
\aleph_{f}[f(\zeta, p)]= & \phi_{1}\left[1+\frac{3(n-1)}{2} W e\left(\frac{\partial^{2} f(\zeta, p)}{\partial \zeta^{2}}\right)^{2}\right] \frac{\partial^{3} f(\zeta, p)}{\partial \zeta^{3}}+ \\
& \phi_{2} \beta^{2}\left[f(\zeta, p) \frac{\partial^{2} f(\zeta, p)}{\partial \zeta^{2}}-\left(\frac{\partial f(\zeta, p)}{\partial \zeta}\right)^{2}-S\left(\frac{\partial f(\zeta, p)}{\partial \zeta}+\frac{\zeta}{2} \frac{\partial^{2} f(\zeta, p)}{\partial \zeta^{2}}\right)\right]-\phi_{3} M \frac{\partial f(\zeta, p)}{\partial \zeta} \cos ^{2} A,
\end{aligned}
$$




$$
\begin{aligned}
& \aleph_{\theta}[f(\zeta, p), \theta(\zeta, p)]=\left(\phi_{4}+N r\right) \frac{\partial^{2} \theta(\zeta, p)}{\partial \zeta^{2}}+ \\
& \phi_{5} \operatorname{Pr}(\beta)^{2}\left[2 \frac{\partial f(\zeta, p)}{\partial \zeta} \theta(\zeta, p)-f(\zeta, p) \frac{\partial \theta(\zeta, p)}{\partial \zeta}+\frac{3}{2} S \theta(\zeta, p)+\frac{1}{2} S \zeta \frac{\partial \theta(\zeta, p)}{\partial \zeta}\right]+A_{3} \frac{\partial f(\zeta, p)}{\partial \zeta}+A_{4} \theta(\zeta, p),
\end{aligned}
$$

Zeroth-order deforming descriptions are

$$
\begin{gathered}
(1-p) \boldsymbol{L}_{f}\left[f(\zeta, p)-f_{0}(\zeta)\right]=p h \aleph_{f}[f(\zeta, p)], \\
(1-p) \boldsymbol{L}_{\theta}\left[\theta(\zeta, p)-\theta_{0}(\zeta)\right]=p h \aleph_{\theta}[f(\zeta, p), \theta(\zeta, p)],
\end{gathered}
$$

accompanying assisting informations

$$
\begin{gathered}
f(0, p)=0, \quad f^{\prime}(0, p)=1, \quad f^{\prime}(\beta, p)=0, \quad f(\beta, p)=\frac{\beta S}{2} . \\
\theta(0, p)=1, \quad \theta^{\prime}(\beta, p)=0 .
\end{gathered}
$$

Implementing Taylor series expansion and Equations (26) and (27), furnish

$$
\begin{gathered}
f(\zeta, p)=f_{0}(\zeta)+\sum_{m=1}^{\infty} f_{m}(\zeta) p^{m}, \quad f_{m}(\zeta)=\left.\frac{1}{m !} \frac{\partial^{m} f(\zeta, p)}{\partial p^{m}}\right|_{p=0} \\
\theta(\zeta, p)=\theta_{0}(\zeta)+\sum_{m=1}^{\infty} \theta_{m}(\zeta) p^{m}, \quad \theta_{m}(\zeta)=\left.\frac{1}{m !} \frac{\partial^{m} \theta(\zeta, p)}{\partial p^{m}}\right|_{p=0} .
\end{gathered}
$$

For convergence, $h$ is adopted through the values that the series (30) and (31) is coincident at $p=1$, hence proceeding to

$$
\begin{aligned}
& f(\zeta)=f_{0}(\zeta)+\sum_{m=1}^{\infty} f_{m}(\zeta) \\
& \theta(\zeta)=\theta_{0}(\zeta)+\sum_{m=1}^{\infty} \theta_{m}(\zeta)
\end{aligned}
$$

3.2. mth-Order Deformation Problems

$$
\begin{gathered}
\boldsymbol{L}_{f}\left[f_{m}(\zeta)-\chi_{m} f_{m-1}(\zeta)\right]=h R_{m}^{f}(\zeta), \\
f_{m}(0)=f_{m}(\beta)=f_{m}^{\prime}(0)=f_{m}^{\prime \prime}(\beta)=0,
\end{gathered}
$$

where

$$
\begin{aligned}
R_{m}^{f}(\zeta)= & \phi_{1}\left[f_{m-1}^{\prime \prime \prime}+\frac{3(n-1)}{2} W e \sum_{k=o}^{m-1} f_{m-1-k}^{\prime \prime \prime} \sum_{l=o}^{k} f_{k-l}^{\prime \prime} f_{l}^{\prime \prime}\right]+ \\
& \phi_{2} \beta^{2}\left[\sum_{k=o}^{m-1} f_{m-1-k} f_{k}^{\prime \prime}-\sum_{k=o}^{m-1} f_{m-1-k}^{\prime} f_{k}^{\prime}-S\left(f_{m-1}^{\prime}+\frac{\zeta}{2} f_{m-1}^{\prime \prime}\right)\right]-\phi_{3} M f_{m-1}^{\prime} \cos ^{2} A .
\end{aligned}
$$

And

$$
\begin{gathered}
\boldsymbol{L}_{\theta}\left[\theta_{m}(\zeta)-\chi_{m} \theta_{m-1}(\zeta)\right]=h R_{m}^{\theta}(\zeta) \\
\theta_{m}(0)=\theta_{m}^{\prime}(\beta)=0
\end{gathered}
$$

where

$$
\begin{aligned}
& R_{m}^{\theta}(\zeta)=\left(\phi_{4}+N r\right) \theta_{m-1}^{\prime \prime}-\phi_{5} \operatorname{Pr} \beta^{2}\left[2 \sum_{k=0}^{m-1} f_{m-1-k}^{\prime} \theta_{k}^{\prime}-\sum_{k=0}^{m-1} f_{m-1-k} \theta_{k}^{\prime}+\frac{3}{2} S \theta_{m-1}+\frac{1}{2} S \zeta \theta_{m-1}^{\prime}\right]+ \\
& A_{3} f_{m-1}^{\prime}+A_{4} \theta_{m-1},
\end{aligned}
$$




$$
\chi_{m}= \begin{cases}0, & m \leq 1 \\ 1, & m>1 .\end{cases}
$$

The solution becomes

$$
\begin{gathered}
f_{m}(\zeta)=f_{m}^{*}(\zeta)+C_{1}+C_{2} \zeta+C_{3} \zeta^{2} \\
\theta_{m}(\zeta)=\theta_{m}^{*}(\zeta)+C_{4}+C_{5} \zeta
\end{gathered}
$$

\section{Results and Discussion}

To discuss the problem solution, an explanation of all the symbols and parameters is necessary. Detail of all the symbols and parameters used in different equations are given in nomenclature. For analytical calculation, the values of different parameters are taken as $\phi=0.40, n=1.50$, We $=0.50$, $\beta=0.10, S=0.50, M=2.00, A=\frac{\pi}{4}, N r=1.00, P r=10.00, A_{3}=0.20$, and $A_{4}=0.20$ in drawing the graphs. The effects of embedded parameters on the velocity $f^{\prime}(\zeta)$ and temperature $\theta(\zeta)$ fields have been plotted in Figures 4-11 and Figures 12-19 respectively. The physical representation of the problem is demonstrated in Figure 1 . The valid $h$-curves [30] to $f(\zeta)$ and $\theta(\zeta)$ are plotted with numerical values $-10.00 \leq h \leq-0.00$ and $-1.20 \leq h \leq-0.20$ in Figures 2 and 3, respectively.

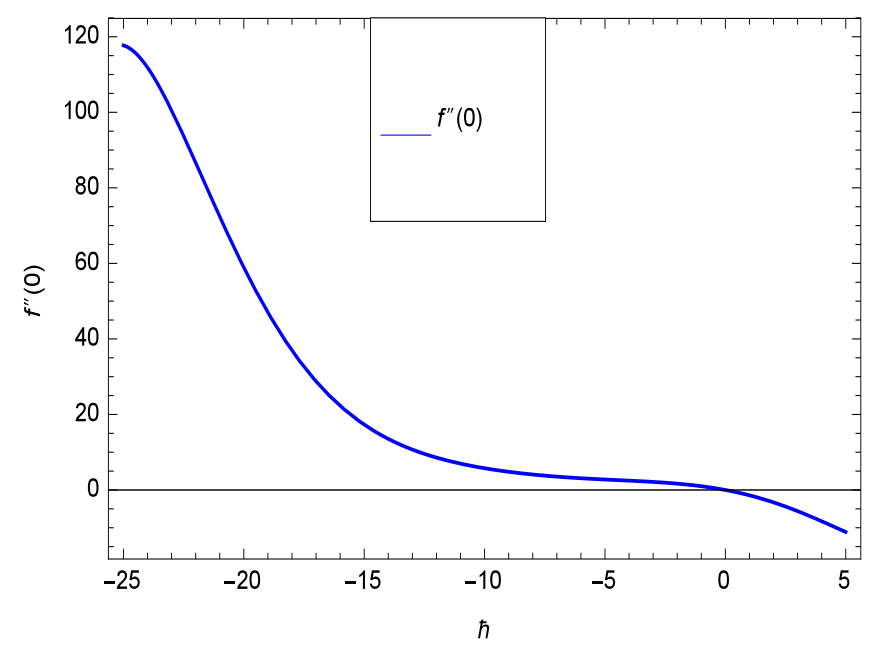

Figure 2. $h$ curve of $f(\zeta)$.

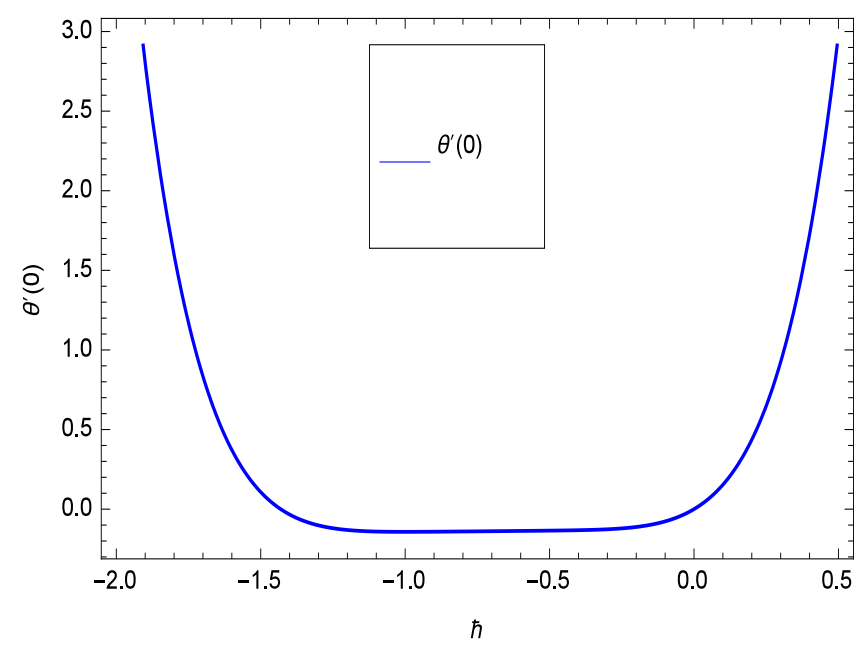

Figure 3. $h$ curve of $\theta(\zeta)$. 


\section{Discussion}

\subsection{Velocity Profile}

We begin with the effect of film size representative $\beta$ on the velocity $f^{\prime}(\zeta)$ profile whose schematic illustration is given in Figure 4. The graphene layer is controlled by film thickness which exhibits that graphene nanofluid velocity reduces when the thin film parameter $\beta$ increases, since by the combination of graphene nanoparticles in the base suspension the graphene layer becomes very heavy. A closer look at the Figure 5 shows that the velocity $f^{\prime}(\zeta)$ of graphene layer depreciates by increasing graphene nanoparticles concentration $\phi$. This clearly indicates that the numbers of graphene nanoparticles are intensified by increasing concentration $\phi$, which implies that graphene nanoparticles are incorporated to resist the motion. The intensity of concentration feature is improved, observing the addition of particle motion which retains a quantity of graphene nanoparticles. Evidently the base fluid contains graphene nanoparticles which do not allow the layer to move fast. Another interesting feature of the particles under consideration is viewed in Figure 6. A schematic representation of the effect of time reliant representative $S$ on the scaled velocity $f^{\prime}(\zeta)$ profile is shown. Apparently, the velocity decreases with the rise of $S$. Velocity profile $f^{\prime}(\zeta)$ becomes stable with metallic graphene nanoparticles with the passage of time.

When magnetic field is imposed, the charged graphene nanoparticles push forward towards the electrode, proceeding the conduction. The conductivity of the graphene nanoparticles is of technological importance. The conductivity of a colloidal dispersion containing graphene nanoparticles is nontrivially reliant to the conduction background, the graphene nanoparticle size, the graphene nanoparticle loading, and the charge of the graphene nanoparticle. In other words, it is stated that the graphene particles are electric current-inducing in the suspension. There exists an electricity double-layer near each graphene nanoparticle surface. The charge on the surface of the graphene nanoparticles in combination with ion cloud constituting the electrical double-layer which enhances the conduction. The particles become positively charged at the time the dielectric constant bears greater values in comparison to those of the base suspension. So in the presence of an inclined magnet environment the graphene layer improves with increasing the magnitude of magnetic field representative $M$, as viewed in Figure 7.

To elucidate the behavior of power law index $n$, Figure 8 is prepared. It is noted that for $n=1.50$ to $n=3.00$, the non-Newtonian effect strongly increases, which stabilizes the Carreau fluid with the existence of graphene particles. In nano-dispersion, the dynamic viscosity is sensitive to the change in saturation of the nano-dispersion. For instance, the dynamic viscosity increases on increasing the volume fraction. Therefore, the velocity $f^{\prime}(\zeta)$ of non-Newtonian Carreau graphene nanofluid decreases as depicted in Figure 8. Upon seeing Figure 9, it is evidenced that on the Weissenberg number We increment, the flow reduces. Namely, the intensity of motion is strongly affected by the Weissenberg number $W e$ in the presence of graphene nanoparticles impurities. It can be obviously seen that Figures 10 and 11 are prepared for the role of inclination angle $A$ of magnetic field. In the analytical solution a fixed value of $A=\frac{\pi}{4}=0.707$ is used. To analyze the magnetic field effect, the angle of inclination is considered for various values of $A$ or $\cos A$, i.e., the effects of $0.000 \leq \cos A \leq 0.707$ and $0.707 \leq \cos A \leq 1.000$ are checked in Figures 10 and 11, respectively. Figure 10 shows that when the angle of inclination increases $\cos A$ decreases, which shows that the velocity $f^{\prime}(\zeta)$ of non-Newtonian Carreau graphene nanofluid decreases. Anyhow, it is stressed that this procedure is made of prime motivation when the angle of inclination decreases, as $\cos A$ increases in Figure 11 where velocity $f(\zeta)$ amplifies. The small increment in $\cos A$ is consistent with rising velocity $f^{\prime}(\zeta)$. 


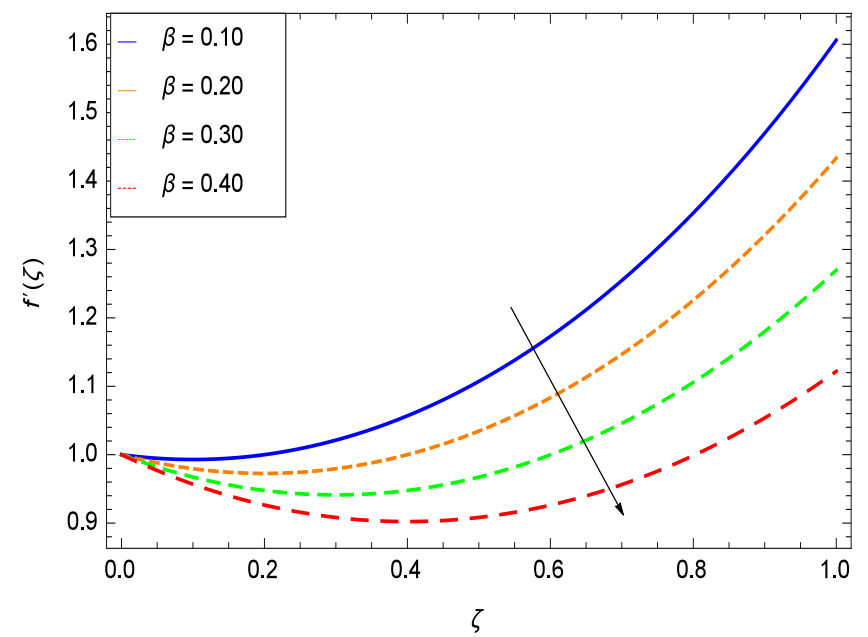

Figure 4. Flow layer at $h=-3.00, \phi=0.40, n=1.50, W e=0.50, S=0.50, M=2.00, A=\frac{\pi}{4}$ with the enhancement in $\beta$.

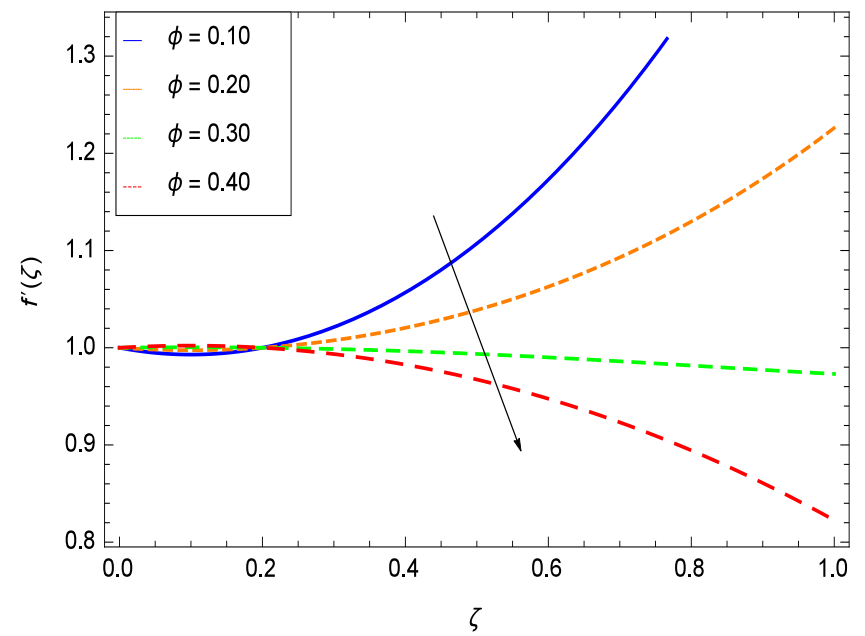

Figure 5. Flow layer at $h=-3.00, \beta=0.10, n=1.50, W e=0.50, S=0.50, M=2.00, A=\frac{\pi}{4}$ with the enhancement in $\phi$.

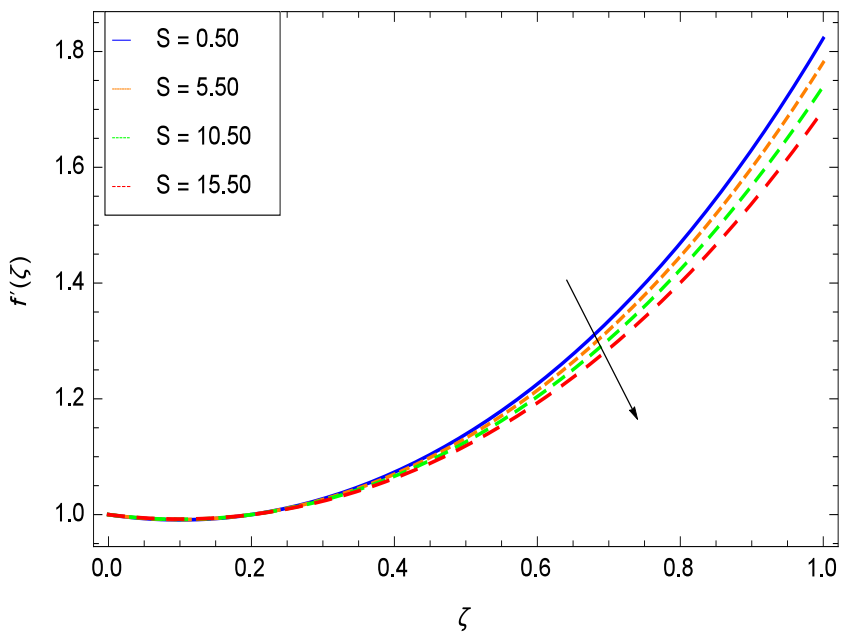

Figure 6. Flow layer at $h=-3.00, \beta=0.10, \phi=0.40, n=1.50, W e=0.50, M=2.00, A=\frac{\pi}{4}$ with the enhancement in $S$. 


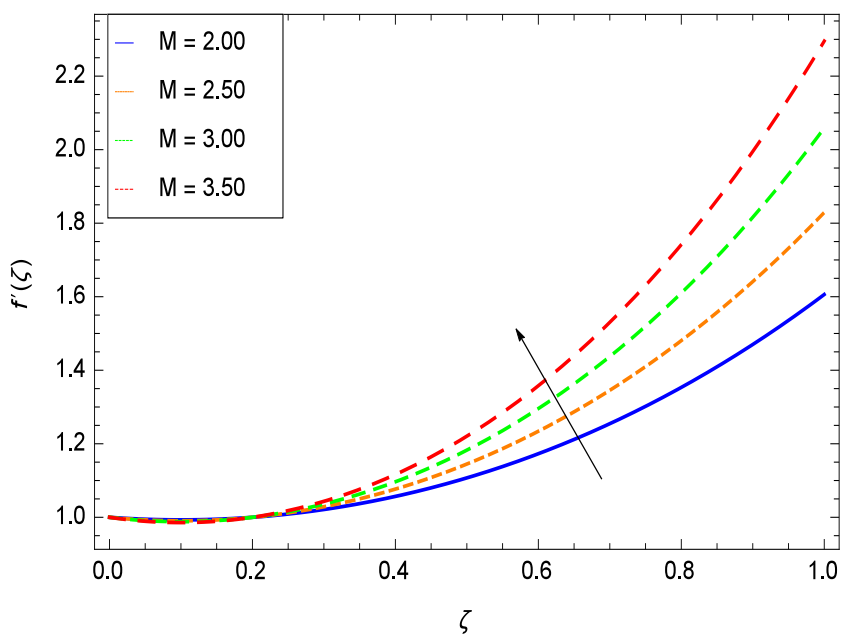

Figure 7. Flow layer at $h=-3.00, \beta=0.10, \phi=0.40, n=1.50, W e=0.50, S=0.50, A=\frac{\pi}{4}$ with the enhancement in $M$.

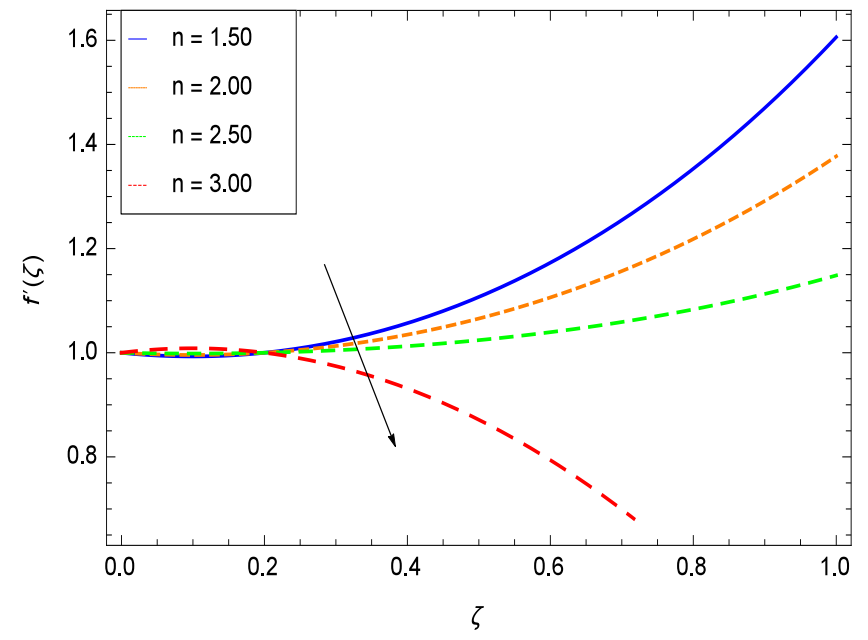

Figure 8. Flow layer at $h=-3.00, \beta=0.10, \phi=0.40, M=2.00, W e=0.50, S=0.50, A=\frac{\pi}{4}$ with the enhancement in $n$.

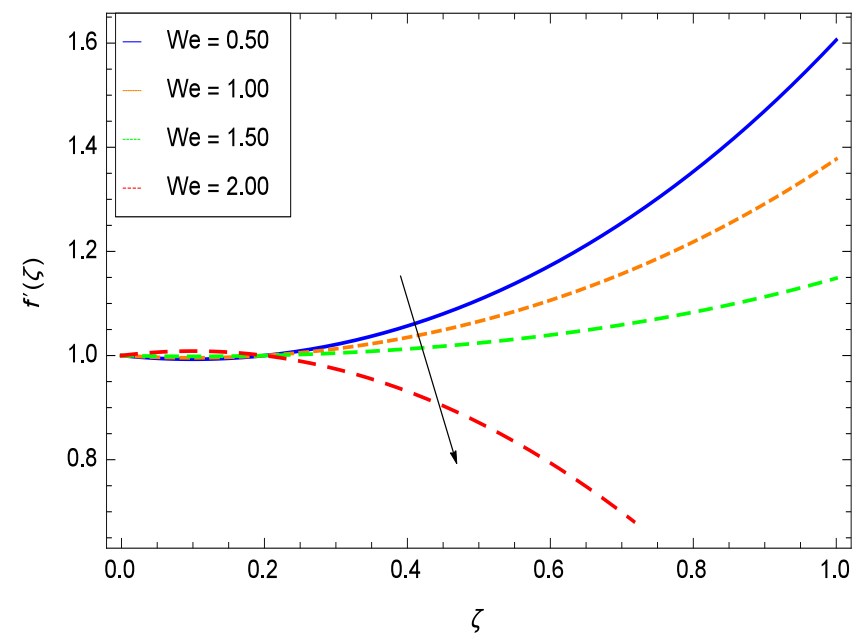

Figure 9. Flow layer at $h=-3.00, \beta=0.10, \phi=0.40, M=2.00, n=1.50, S=0.50, A=\frac{\pi}{4}$ with the enhancement in We. 


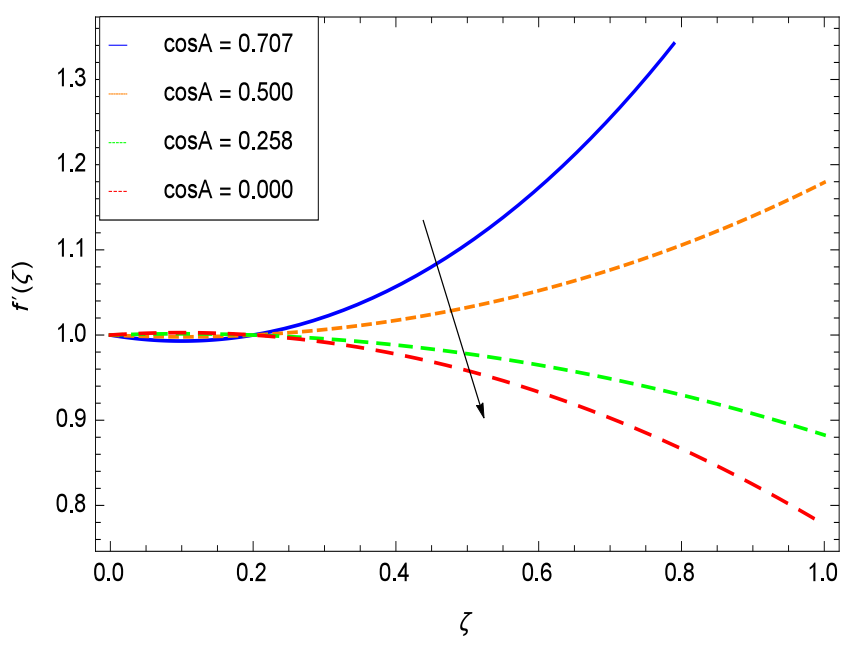

Figure 10. Flow layer at $h=-3.00, \beta=0.10, \phi=0.40, M=2.00, n=1.50, S=0.50, W e=0.50$ with the enhancement in $\cos A$.

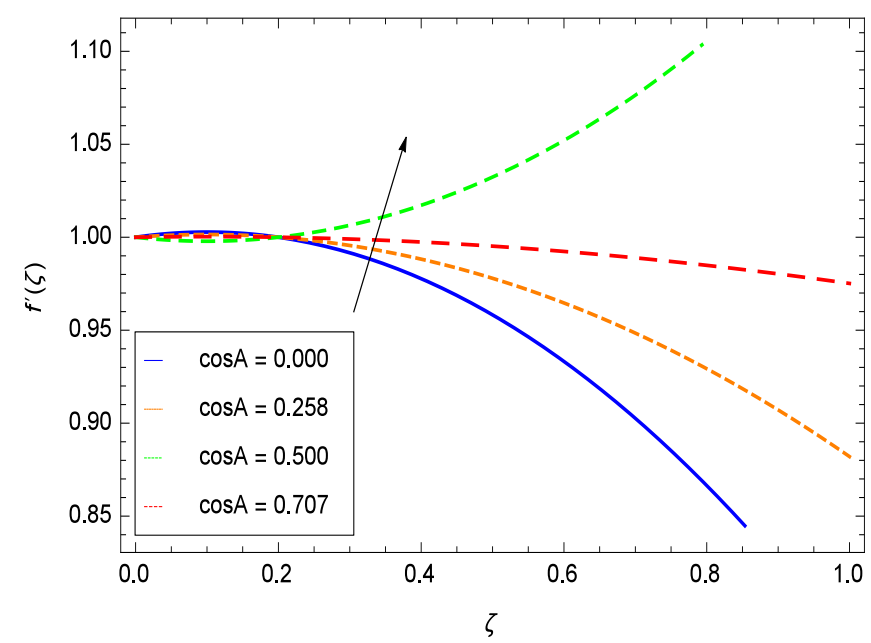

Figure 11. Flow layer at $h=-3.00, \beta=0.10, \phi=0.40, M=2.00, n=1.50, S=0.50$, We $=0.50$ with the enhancement in $\cos A$.

\subsection{Temperature Profile}

Most importantly, the energy position is affected by the amount of embedded graphene nanoparticles. From Figure 12, it allows that the energy representative $\theta(\zeta)$ increases as the quantities of film size representative $\beta$ increase, due to the existence of graphene nanoparticles which have an active role in thermal conductivity. It is straightforward to say and interpret that the conduction in graphene nanoparticles is due to the free electrons.

To obtain further insight into the analysis, concentration is analyzed. Graphene nanoparticles have a well known contribution to electrical conductivity. For this phenomenon, graphene nanofluid concentration $\phi$ is successfully applied, the effect of which is shown in Figure 13, illustrating that energy $\theta(\zeta)$ increases as the graphene nanofluid concentration $\phi$ enhances. The amount of current in the conducting band of graphene is due to charge carrier density, which is measured in electrons. It is anticipated that the present approach enforces further progress in application of graphene nanoparticles for improved electricity usages. Heat transfer increases with graphene nanofluid velocity and graphene nanoparticle saturation, which enhances the heating delivery capability of the graphene nanofluid in comparison to the pure liquid. Moreover, heat transfer is greatly affected by the particle's Brownian movement heat-dependent physical characteristics, such as viscosity and thermal conductivity. It 
also depends on the specific area of the graphene nanoparticles. This notion is lead by the graphene nanofluid concentration $\phi$, which conveys the concept that the $\theta(\zeta)$ profile develops as $\phi$ rises in Figure 13.

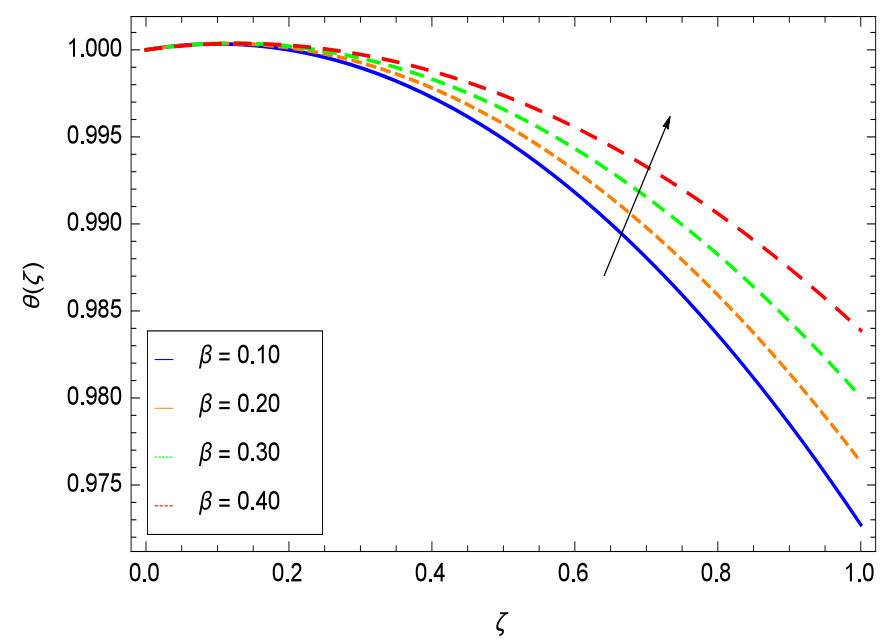

Figure 12. Conduction layer at $h=-3.00, \phi=0.40, n=1.50, W e=0.50, S=0.50, M=2.00, N r=1.00$, $\operatorname{Pr}=10.00, A_{3}=A_{4}=0.20, A=\frac{\pi}{4}$ with the enhancement in $\beta$.

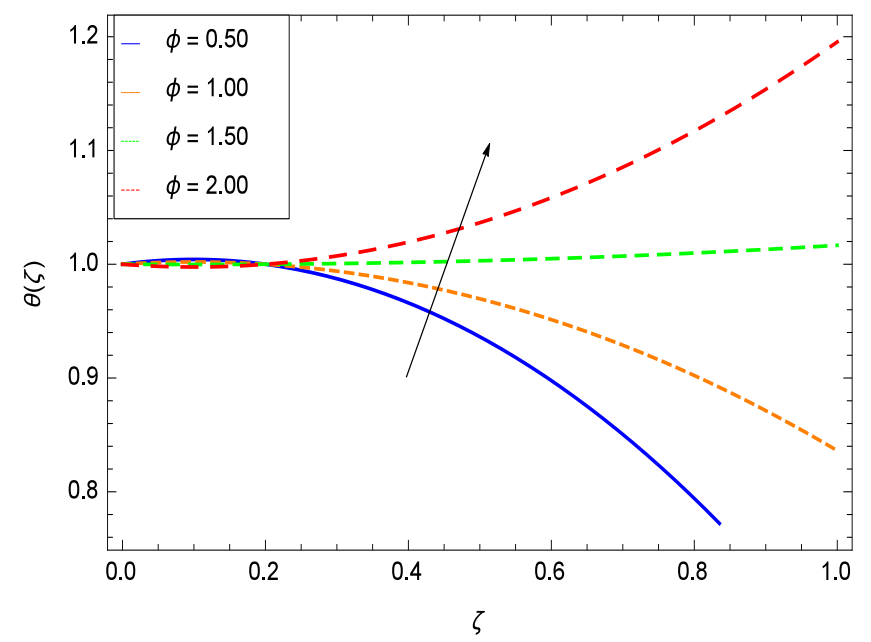

Figure 13. Conduction layer at $h=-1.80, \beta=0.10, n=1.50, \mathrm{We}=0.50, S=0.50, M=2.00, N r=1.00$, $\operatorname{Pr}=10.00, A_{3}=A_{4}=0.20, A=\frac{\pi}{4}$ with the enhancement in $\phi$.

The impact of magnet environment representative $M$ on heating $\theta(\zeta)$ is shown in Figure 14 . The magnet environment of magnitude $B_{0}$ is imposed in an inclined position at an angle $A=\frac{\pi}{4}$ to the space, which makes a hurdle and overcomes the movement. The resistivity of magnetic field depends on the angle $A=\frac{\pi}{4}$. In the current study exploration, the fluid is a Carreau fluid and the occurrence of graphene particles constitutes the increasing energy $\theta(\zeta)$ with the incorporation of magnet environment. In Figure 15, one can see the output of representative $A_{3}$. It reveals that heating $\theta(\zeta)$ falls down for the greater quantities of $A_{3}$. The effect of representative $A_{4}$ is depicted in Figure 16 which shows that the temperature $\theta(\zeta)$ is greatly reduced with the rising magnitude of $A_{4}$. The cumulative impact of the space and temperature-reliant heating inlet/outlet representatives $\left(A_{3}, A_{4}\right)$ are responsible for evaluating the limit to which the energy diminishes or elevates in the motion regime. In the present case, the energy is absorbed for developing quantities of space-dependent and energy-reliant heating inlet/outlet representatives $\left(A_{3}, A_{4}\right)$, reducing the temperature greatly. Moreover, it may be proved 
that the thermal boundary layer for the heating source is thicker than the heat sink case. The effect of thermal radiation parameter $N r$ is shown in Figure 17, demonstrating that temperature increases when radiation takes place because heat is emitted in radiation. The background of this phenomenon is that as thermal radiation representative $N r$ is maximized, mean Rosseland penetrating coefficient $k_{1}$ decreases, which causes development in energy. Figure 18 views the impact of unsteady representative $S$, conveying the message that with the passage of time, the temperature increases. Figure 19 explains that temperature decreases as the Prandtl number Pr increases, so cooling or heating can be controlled by this parameter.

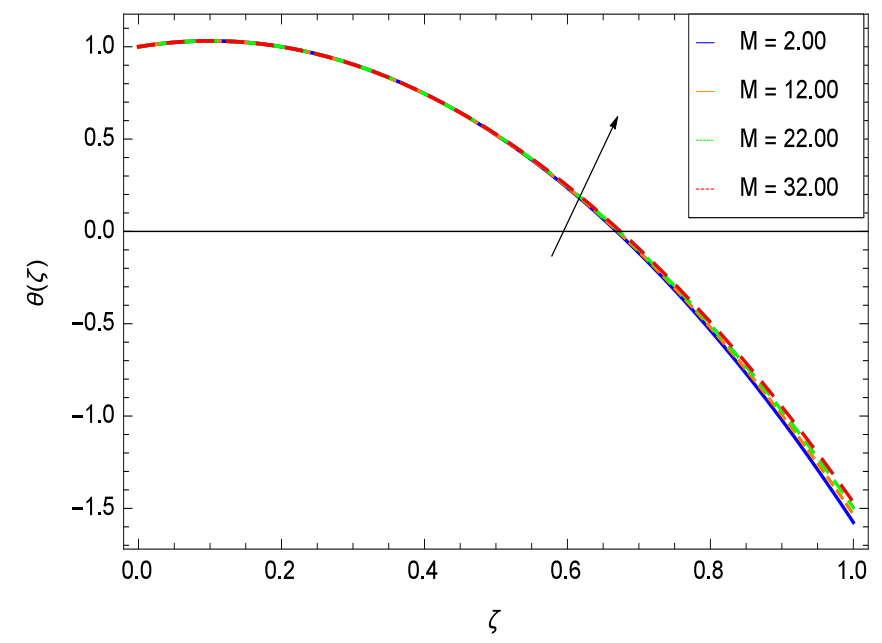

Figure 14. Conduction layer at $h=-3.00, \beta=0.10, \phi=0.40, n=1.50, \mathrm{We}=0.50, S=0.50, \mathrm{~N} r=1.00$, $\operatorname{Pr}=10.00, A_{3}=A_{4}=0.20, A=\frac{\pi}{4}$ with the enhancement in $M$.

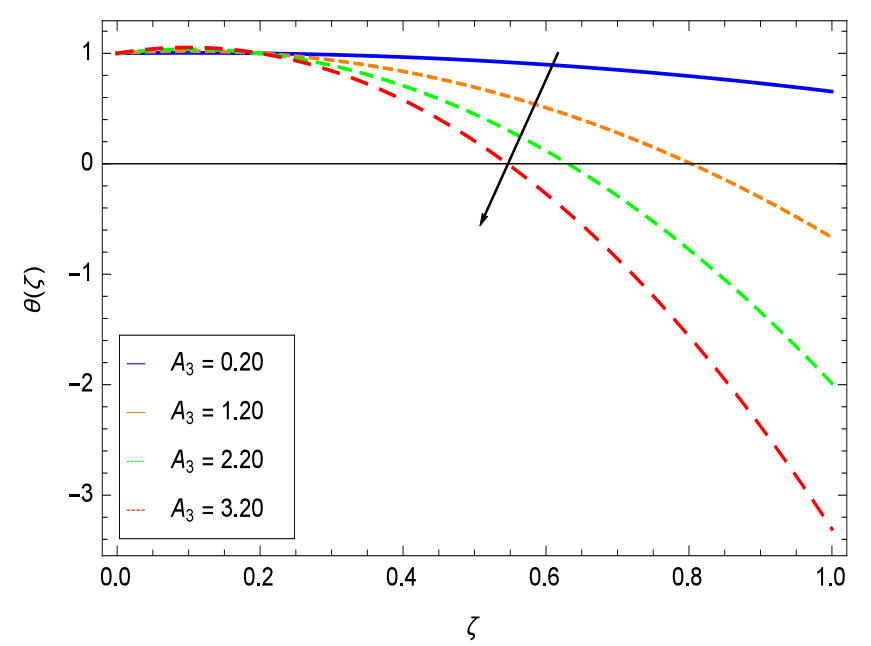

Figure 15. Conduction layer at $h=-1.80, \beta=0.10, \phi=0.40, n=1.50, W e=0.50, S=0.50, N r=1.00$, $M=2.00, \operatorname{Pr}=10.00, A_{4}=0.20, A=\frac{\pi}{4}$ with the enhancement in $A_{3}$. 


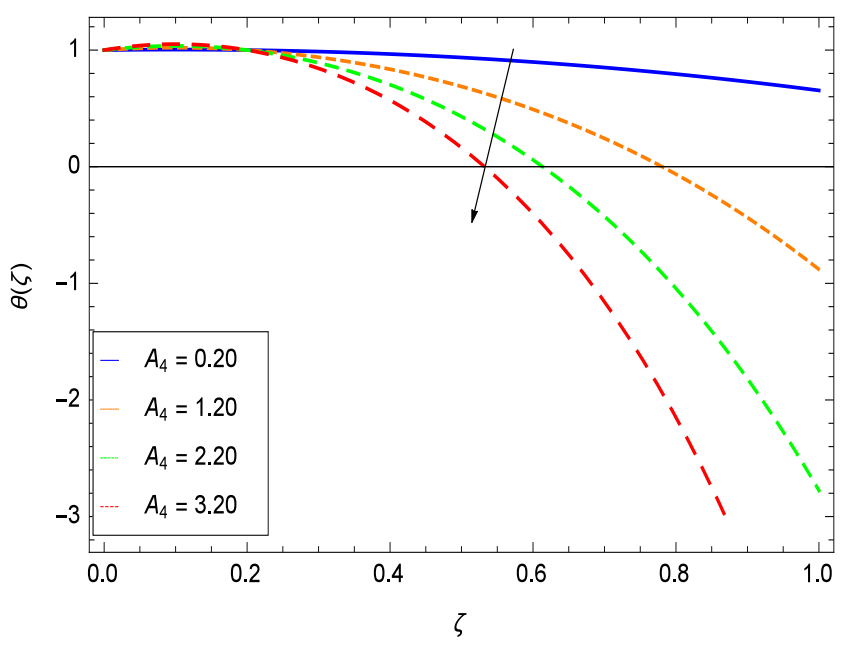

Figure 16. Conduction layer at $h=-1.80, \beta=0.10, \phi=0.40, n=1.50, W e=0.50, S=0.50, N r=1.00$, $M=2.00, \operatorname{Pr}=10.00, A_{3}=0.20, A=\frac{\pi}{4}$ with the enhancement in $A_{4}$.

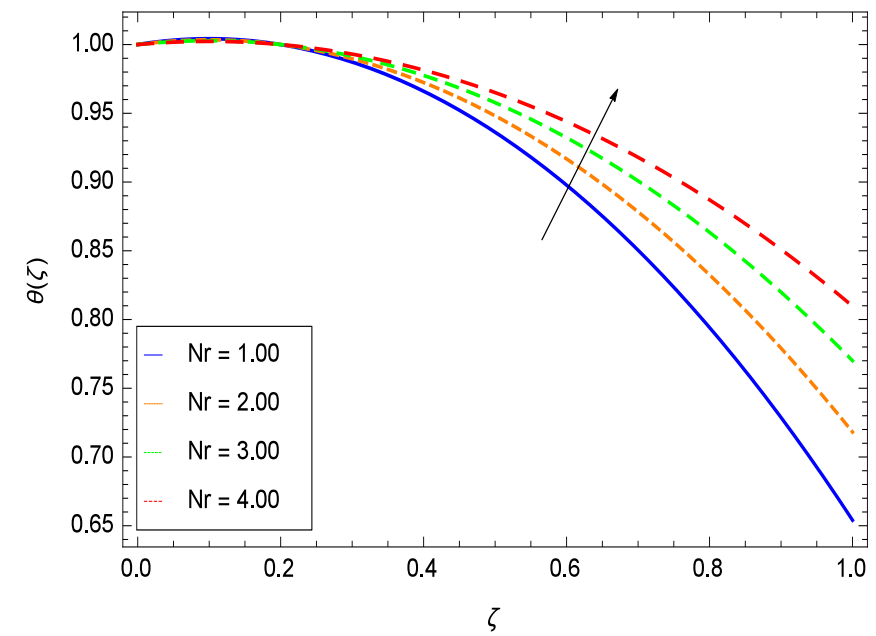

Figure 17. Conduction layer at $h=-3.00, \beta=0.10, \phi=0.40, n=1.50, S=0.50, M=2.00, \operatorname{Pr}=10.00$, $A_{3}=A_{4}=0.20, W e=0.50, A=\frac{\pi}{4}$ with the enhancement in $N r$.

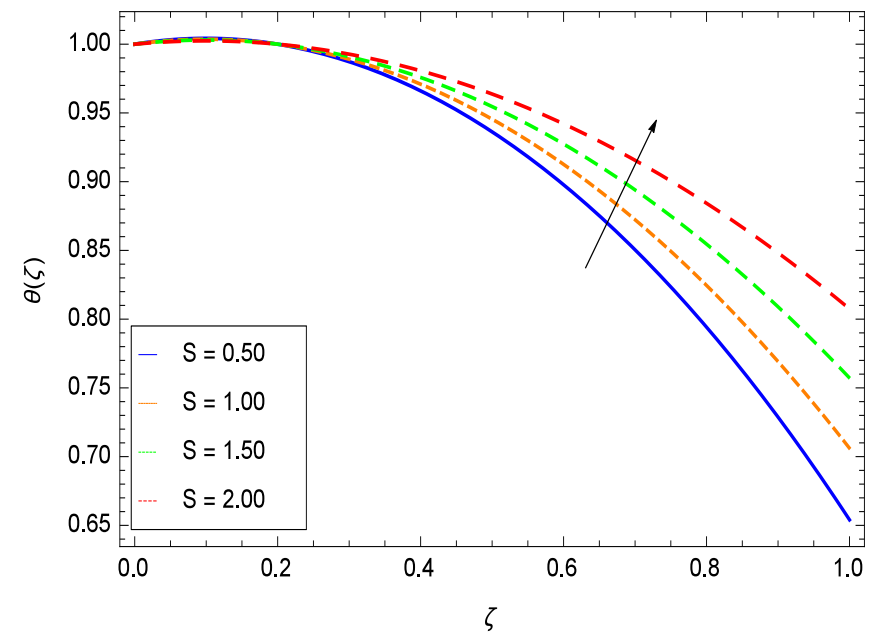

Figure 18. Conduction layer at $h=-1.80, \beta=0.10, \phi=0.40, n=1.50, \mathrm{We}=0.50, M=0.50, \mathrm{Nr}=1.00$, $\operatorname{Pr}=10.00, A_{3}=A_{4}=0.20, A=\frac{\pi}{4}$ with the enhancement in $S$. 


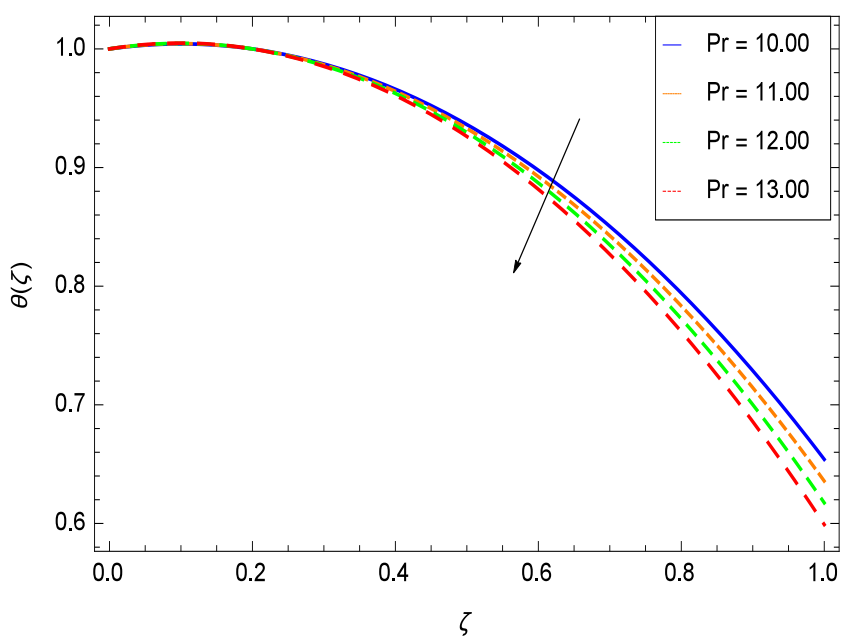

Figure 19. Conduction layer at $h=-1.80, \beta=0.10, \phi=0.40, n=1.50, \mathrm{We}=0.50, M=0.50, \mathrm{Nr}=1.00$, $S=0.50, A_{3}=A_{4}=0.20, A=\frac{\pi}{4}$ with the enhancement in $P r$.

\subsection{Comparison of the Present Work}

The nanoproduct of carbon, like carbon nanotubes, and the product of graphene, like few-layer graphene, reduced oxidized graphene, and nanosheets of graphene, have attracted special attention from scientists and industrial researchers on the basis of their extensive usages in the fields of bio-genesis, bio-medicinal techniques, and nano-tools. The local Nusselt number $(\mathrm{Nu})$ and skin friction coefficient $\left(C_{f}\right)$ are the important quantities for the aforementioned terminologies.

Tables 2 and 3 provide data of the present and published works, which correspond a nice tendency with respect to the behaviors of different profiles like skin friction, surface temperature, and wall temperature gradient. In these comparisons, some parameters are fixed while the behaviors are observed through the variation of some other parameters.

Table 2. Comparison of values of film thickness $\beta$ and skin friction coefficient $f^{\prime \prime}(0)$ for different values of $S$ when $\phi=A_{3}=A_{4}=M=0, \operatorname{Pr}=10.00$, and $h=-0.10$.

\begin{tabular}{ccccc}
\hline Parameter & \multicolumn{2}{c}{ Mahmoud and Megahed [29] } & \multicolumn{2}{c}{ Present Results } \\
\hline S & $\boldsymbol{\beta}$ & $-f^{\prime \prime}(0)$ & $\boldsymbol{\beta}$ & $-f^{\prime \prime}(0)$ \\
\hline 0.4 & 4.981455 & 1.134096 & 4.981455 & 1.134095 \\
0.6 & 3.131711 & 1.195125 & 3.131711 & 1.195123 \\
0.8 & 2.151992 & 1.245805 & 2.151992 & 1.245803 \\
1.0 & 1.543616 & 1.277769 & 1.543616 & 1.277768 \\
1.2 & 1.127781 & 1.279171 & 1.127781 & 1.279173 \\
1.4 & 0.821032 & 1.233545 & 0.821032 & 1.233546 \\
1.6 & 0.576175 & 1.114939 & 0.576175 & 1.114938 \\
1.8 & 0.356389 & 0.867416 & 0.356389 & 0.867415 \\
\hline
\end{tabular}


Table 3. Comparison of values of surface temperature and wall temperature gradient with increasing values of $\operatorname{Pr}, S$ and $\beta$ when $\phi=A_{3}=A_{4}=M=0$, and $h=-0.10$.

\begin{tabular}{ccccccc}
\hline \multicolumn{3}{c}{ Parameters } & \multicolumn{2}{c}{ Mahmoud and Megahed [29] } & \multicolumn{2}{c}{ Present Results } \\
\hline $\boldsymbol{P r}$ & $\boldsymbol{S}$ & $\boldsymbol{\beta}$ & $\boldsymbol{\theta}(\boldsymbol{\beta})$ & $-\boldsymbol{\theta}^{\prime} \mathbf{( 0 )}$ & $\boldsymbol{\theta}(\boldsymbol{\beta})$ & $-\boldsymbol{\theta}^{\prime} \mathbf{( 0 )}$ \\
\hline 0.01 & 0.8 & 2.151990 & 0.960440 & 0.042023 & 0.960441 & 0.042024 \\
0.1 & 0.8 & 2.151990 & 0.692268 & 0.351319 & 0.692265 & 0.351318 \\
1.0 & 0.8 & 2.151990 & 0.097825 & 1.671917 & 0.097823 & 1.671915 \\
2.0 & 0.8 & 2.151990 & 0.024868 & 2.443816 & 0.024864 & 2.443815 \\
3.0 & 0.8 & 2.151990 & 0.008325 & 3.036115 & 0.008324 & 3.036113 \\
0.01 & 1.2 & 1.127780 & 0.982311 & 0.033417 & 0.982312 & 0.033418 \\
0.1 & 1.2 & 1.127780 & 0.843485 & 0.305406 & 0.843484 & 0.305407 \\
1.0 & 1.2 & 1.127780 & 2.86635 & 1.773774 & 2.86634 & 1.773775 \\
2.0 & 1.2 & 1.127780 & 0.128174 & 2.638433 & 0.128173 & 2.638435 \\
3.0 & 1.2 & 1.127780 & 0.067738 & 3.280327 & 0.067739 & 3.280325 \\
\hline
\end{tabular}

\section{Conclusions}

The problem is modeled and solved. During the modeling, some parameters are originated due to scaling. It is mandatory to discuss the potentiality of all the parameters.

The summary of the conclusion is represented as follows.

(1) The velocity $f^{\prime}(\zeta)$ decreases with $\beta, \phi, S, n, W e$, and increasing $A$, and increases with $M$ and reducing $A$.

(2) The temperature $\theta(\zeta)$ decreases with $\beta, S, n, W e$, and increasing $A$, and increases with $\phi, M$ and reducing $A$.

(3) The skin friction coefficient $f^{\prime \prime}(0)$ mitigates on elevating $S$ and decreasing value of $\beta$.

(4) The energy on surface $\theta(\beta)$ and energy gradient at wall $\theta^{\prime}(0)$ both decrease with increasing Prandtl number.

\section{Future Work}

It is strongly believed that the present study provides a good scope to elucidate the improved heating conduction of non-Newtonian dispersion, showing enhanced thermal conductivity by dispersing the graphene nanoparticles.

Author Contributions: Conceptualization, N.S.K.; methodology, N.S.K.; software, T.G.; validation, P.K.; formal analysis, W.K.; investigation, S.I.; resources, A.S.; data curation, Z.S.; writing—original draft preparation, N.S.K.; writing-review and editing, N.S.K.; visualization, S.Z.; supervision, N.S.K.

Funding: This research was funded by the Center of Excellence in Theoretical and Computational Science (TaCS-CoE), KMUTT.

Acknowledgments: This project was supported by the Theoretical and Computational Science (TaCS) Center under Computationaland Applied Science for Smart Innovation Research Cluster (CLASSIC), Faculty of Science, KMUTT.

Conflicts of Interest: The authors declare no conflict of interest.

\section{Nomenclature}

$\begin{array}{ll}M & \text { Magnetic field parameter } \\ m & \mathrm{~m} \text {-th order } \\ n & \text { Power law index } \\ W e & \text { Weissenberg number } \\ \mathrm{Nr} & \text { Thermal radiation parameter } \\ \mathrm{Pr} & \text { Prandtl number } \\ k & \text { Thermal conductivity }\left(\mathrm{m}^{2} \mathrm{~s}^{-1}\right) \\ k_{1} & \text { Mean absorption coefficient } \\ t & \text { Time }(\mathrm{s})\end{array}$




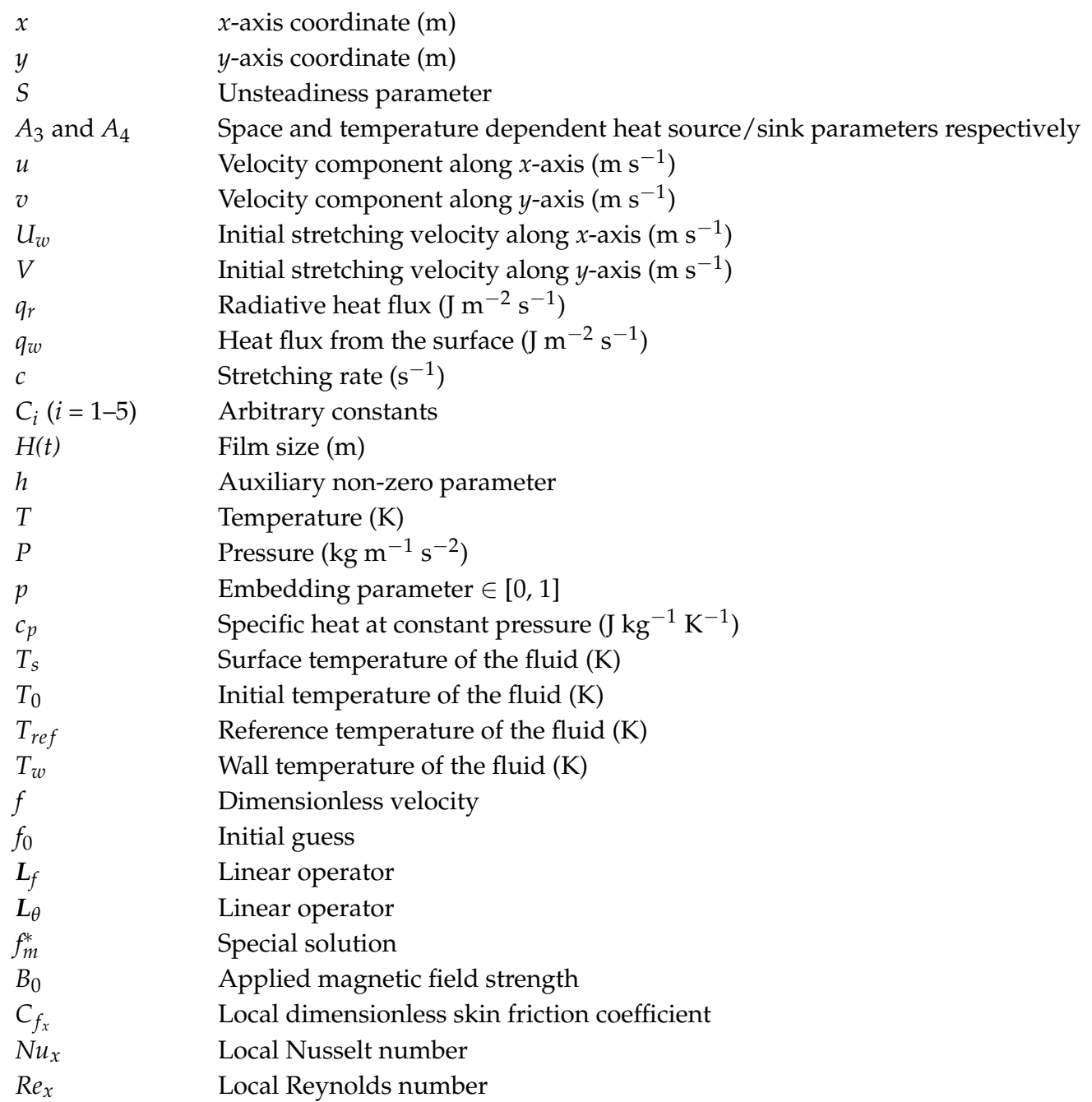

Greek symbols

$\begin{array}{ll}\phi & \text { Volume fraction of the graphene nanoparticles } \\ \phi_{i}(i=1-5) & \text { Nanofluid constants } \\ \alpha & \text { Constant }\left(\mathrm{s}^{-1}\right) \\ \sigma & \text { Electrical conductivity } \\ \sigma_{1} & \text { Stefan-Boltzmann constant } \\ \psi & \text { Physical stream function }\left(\mathrm{m}^{2} \mathrm{~s}^{-1}\right) \\ \beta & \text { Dimensionless fluid thickness parameter } \\ \zeta & \text { Similarity variable } \\ \Gamma & \text { Non-Newtonian time constant } \\ \gamma & \text { Square root of the half of the second invariant strain tensor } \\ \theta & \text { Dimensionless temperature } \\ \theta_{0} & \text { Initial guess } \\ \theta_{m}^{*} & \text { Special solution } \\ \aleph & \text { Non-linear operator } \\ v & \text { Kinematic viscosity }\left(\mathrm{m}^{2} \mathrm{~s}^{-1}\right) \\ \mu_{0} & \text { Zero shear rate viscosity }\left(\mathrm{kg} \mathrm{m}^{-1} \mathrm{~s}^{-1}\right) \\ \Pi & \text { Second invariant strain tensor } \\ \rho & \left.\text { Density (kg m }{ }^{-3}\right) \\ \tau_{w} & \text { Shear stress at the surface }\left(\mathrm{kg} \mathrm{m}^{-1} \mathrm{~s}^{-2}\right)\end{array}$


Subscripts

$\mathrm{s}$

sd

ref

w

nf

$\mathrm{f}$

o

$\mathrm{x}$

Superscripts

Surface

Solid nanoparticles

Reference

Properties at the wall

Nanofluid

Base fluid

Origin

Local value

Differentiation with respect to $\zeta$

\section{References}

1. Khan, N.S.; Zuhra, S.; Shah, Z.; Bonyah, E.; Khan, W.; Islam, S. Slip flow of Eyring-Powell nanoliquid film containing graphene nanoparticles AIP Adv. 2018, 8, 115302 [CrossRef]

2. Sandeep, N.; Malvandi, A. Enhanced heat transfer in liquid film flow of non-Newtonian nanofluids embedded with graphene nanoparticles. Adv. Powder Technol. 2016, 27, 2448-2456. [CrossRef]

3. Zuhra, S.; Khan, N.S.; Khan, M.A.; Islam, S.; Khan, W.; Bonyah, E. Flow and heat transfer in water based liquid film fluids dispensed with graphene nanoparticles. Results Phys. 2018, 8, 1143-1157. [CrossRef]

4. Wu, P.; Qian, Y.; Du, P.; Zhang, H.; Cai, C. Facile synthesis of nitrogen-doped graphene for measuring the releasing process of hydrogen peroxide from living cells. J. Mater. Chem. 2012, 22, 6402-6412, doi:10.1039/c2jm16929k. [CrossRef]

5. Yue, C.; Feng, J.; Feng, J.; Jiang, Y. Low thermal conductivity nitrogen-doped graphene aerogels for thermal insulation. RSC Adv. 2016, 6, 9396-9401. [CrossRef]

6. Sadeghinezhad, E.; Meharali, M.; Latibari, S.T.; Meharali, M.; Kazi, S.N.; Oon, C.S.; Meselaar, H.S.C. Experimental investigation of convective heat transfer using graphene nanoplatelet based nanofluids under turbulent flow conditions. Ind. Eng. Chem. Res. 2014, 53, 12455-12465. [CrossRef]

7. Guo, H.L.; Su, P.; Kang, X.; Ning, S.K. Synthesis and characterization of nitrogen-doped graphene hydrogels by hydrothermal rout with urea as reducing agents. J. Mater. Chem. A 2012. [CrossRef]

8. Meharali, M.; Sadeghinezhad, E.; Latibari, S.T.; Meharali, M.; Togun, H.; Zubir, M.N.M.; Kazi, S.N.; Metselaar, H.S.C. Preparation, characterization, viscosity, and thermal conductivity of nitrogen-doped graphene aqueous nanofluids. J. Mater. Sci. 2014, 49, 7156-7171. [CrossRef]

9. Meharali, M.; Sadeghinezhad, E.; Rashidi, M.M.; Akhiani, A.R.; Latibari, S.T.; Meharali, M.; Metselaar, H.S.C. Experimental and numerical investigation of the effective electrical conductivity of nitrogen-doped graphene nanofluids. J. Nanopart. Res. 2015, 17, 267. [CrossRef]

10. Sheng, Z.H.; Shao, L.; Chen, J.J.; Bao, W.J.; Wang, F.B.; Xia, X.H. Catalyst-free synthesis of nitrogen-doped graphene via thermal annealing graphite oxide with melamine and its excellent electrocatalysis. ACS Nano 2011, 5, 4350-4358 [CrossRef] [PubMed]

11. Reddy, A.L.M.; Srivastava, A.; Gowda, S.R.; Gullapalli, H.; Dubey, M.; Ajayan, P.M. Synthesis of nitrogen-doped graphene films for lithium battery application. ACS Nano 2010, 4, 6337-6342. [CrossRef] [PubMed]

12. Khan, N.S.; Zuhra, Z.; Shah Z.; Bonyah, E.; Khan, W.; Islam, S. Hall current and thermophoresis effects on magnetohydrodynamic mixed convective heat and mass transfer thin film flow. J. Phys. Commun. 2018. [CrossRef]

13. Khan, N.S.; Gul, T.; Khan, M.A.; Bonyah, E.; Islam, S. Mixed convection in gravity-driven thin film non-Newtonian nanofluids flow with gyrotactic microorganisms. Results Phys. 2017, 7, 4033-4049. [CrossRef]

14. Zuhra, S.; Khan, N.S.; Islam, S. Magnetohydrodynamic second grade nanofluid flow containing nanoparticles and gyrotactic microorganisms. Comput. Appl. Math. 2018, 37, 6332-6358. [CrossRef]

15. Khan, N.S. Bioconvection in second grade nanofluid flow containing nanoparticles and gyrotactic microorganisms. Braz. J. Phys. 2018, 43, 227-241. [CrossRef]

16. Palwasha, Z.; Islam, S.; Khan, N.S.; Ayaz, H. Non-Newtonian nanoliquids thin film flow through a porous medium with magnetotactic microorganisms. Appl. Nanosci. 2018, 8, 1523-1544. [CrossRef] 
17. Zuhra, S.; Khan, N.S.; Shah, Z.; Islam, S.; Bonyah, E. Simulation of bioconvection in the suspension of second grade nanofluid containing nanoparticles and gyrotactic microorganisms. AIP Adv. 2018, 8, 105210. [CrossRef]

18. Khan, N.S.; Gul, T.; Islam, S.; Khan, W. Thermophoresis and thermal radiation with heat and mass transfer in a magnetohydrodynamic thin film second-grade fluid of variable properties past a stretching sheet. Eur. Phys. J. Plus 2017, 132. [CrossRef]

19. Palwasha, Z.; Khan, N.S.; Shah, Z.; Islam, S.; Bonyah, E. Study of two-dimensional boundary layer thin film fluid flow with variable thermophysical properties in three dimensions space. AIP Adv. 2018, 8, 105318. [CrossRef]

20. Khan, N.S.; Gul, T.; Islam, S.; Khan, I.; Alqahtani, A.M.; Alshomrani, A.S. Magnetohydrodynamic nanoliquid thin film sprayed on a stretching cylinder with heat transfer. J. Appl. Sci. 2017, 7, 271. [CrossRef]

21. Khan, N.S.; Gul, T.; Islam, S.; Khan, A.; Shah, Z. Brownian motion and thermophoresis effects on MHD mixed convective thin film second-grade nanofluid flow with Hall effect and heat transfer past a stretching sheet. J. Nanofluids 2017, 6, 812-829. [CrossRef]

22. Khan, N.S.; Gul, T.; Islam, S.; Khan, W.; Khan, I.; Ali, L. Thin film flow of a second-grade fluid in a porous medium past a stretching sheet with heat transfer. Alex. Eng. J. 2017. [CrossRef]

23. Khan, N.S.; Shah, Z.; Islam, S.; Khan, I.; Alkanhal, T.A.; Tlili, I. Entropy generation in MHD mixed convection non-Newtonian second-grade nanoliquid thin film flow through a porous medium with chemical reaction and stratification. Entropy 2019, 21, 139. [CrossRef]

24. Khan, N.S.; Zuhra, S.; Shah, Q. Entropy generation in two phase model for simulating flow and heat transfer of carbon nanotubes between rotating stretchable disks with cubic autocatalysis chemical reaction. Appl. Nanosci. 2019. [CrossRef]

25. Sulochana, C.; Ashwinkumar, G.P. Carreau model for liquid thin film flow of dissipative magnetic-nanofluids over a stretching sheet. Int. J. Inf. Technol. 2017, 10, 239-254, doi:10.14257/ijhit.2017.10.1.21. [CrossRef]

26. Raju, C.S.K.; Hoque, M.M.; Khan, N.A.; Islam, M.; Kumar, S. Multiple slip effects on magnetic-Carreau fluid in a suspension of gyrotactic microorganisms over a slendering sheet. Proc. Inst. Mech. Eng. Part E J. Process Mech. Eng. 2018. [CrossRef]

27. Irfan, M.; Khan, W.A.; Khan, M.; Gulzar, M.M. Influence of Arrhenius energy in chemically reactive radiative flow of 3D Carreau nanofluid with nonlinear mixed convection. J. Phys. Chem. Solids 2019, 125, 141-152. [CrossRef]

28. Waqas, M.; Khan, M.I.; Hayat, T.; Alsaedi, A. Numerical simulation for magneto Carreau nanofluid model with thermal radiation: A revised model. Comput. Methods Appl. Mech. Eng. 2017, 324, 640-653. [CrossRef]

29. Mahmoud, M.A.A.; Megahed, A.M. Slip flow of Powell-Eyring liquid film due to an unsteady stretching sheet with heat transfer generation. Braz. J. Phys. 2016. [CrossRef]

30. Liao, S.J. Homotopy Analysis Method in Non-Linear Differential Equations; Higher Education Press: Beijing, China; Springer: Berlin/Heidelberg, Germany, 2012.

(C) 2019 by the authors. Licensee MDPI, Basel, Switzerland. This article is an open access article distributed under the terms and conditions of the Creative Commons Attribution (CC BY) license (http:/ / creativecommons.org/licenses/by/4.0/). 